\title{
THE ROLE OF ORAL HEALTH IN IMPROVING THE ORAL CONDITION OF EXPECTANT MOTHERS AND THEIR NEWBORNS FROM BIRTH THROUGHOUT THE SCHOOL YEARS: A LITERATURE REVIEW
}

\author{
Eman A. El Ashiry*
}

\begin{abstract}
Oral health is an integral part of general health; good oral health is critical to an individual's overall health and well-being. The objective of this literature review is to provide an overview of the role of oral health in prevention of oral diseases and improvement of oral status of expectant mothers and their babies from birth throughout different school stages. Electronic search of English scientific papers from 2006 to 2016 was accomplished using the Cochrance library database, PubMed, the EviDents search engine, the EMBASE database, OVID, and the Science Citation Index database. The search terms used were expectant mother, pregnancy, pregnancy outcome, periodontal diseases, evidence-based dentistry, oral health care, oral health education, clinical recommendations. Maintaining good oral health improves the general health and well-being of women during pregnancy, may reduce adverse pregnancy outcomes and contributes to improving the oral health of their children.
\end{abstract}

KEYWORDS: Expectant mother, pregnancy, pregnancy outcome, periodontal diseases, evidence-based dentistry, oral health care, oral health education, clinical recommendations

\section{INTRODUCTION}

Oral health is an integral part of general health; good oral health is critical to an individual's overall health and well-being. Freedom from mouth and facial pain, tooth decay, tooth loss and other oral conditions helps people stay healthy at every stage of their lives. Poor oral health, on the other hand, can significantly diminish an individual's health status and quality of life $\mathrm{e}^{1-3}$.
Oral health promotion is the science and art with organized efforts that strive to prevent and control oral and craniofacial diseases, helping people and society change their lifestyles to achieve optimal health at the community level. It places an emphasis on improving quantity and quality of life for all and enables the improvement of health ${ }^{4-6}$.

A well-documented physiologic change in the mouth that occur during pregnancy and clinically

* Associate Professor, Pediatric Dentistry Department, Faculty of Dentistry, King Abdulaziz, University, KSA and Pedodontic Department, Faculty of Dental Medicine for Girls Al Azhar University, Egypt 
important alterations in the woman's immune system place pregnant women at higher risk for dental infections. Oral health of pregnant women has the potential to impact the oral health status of their children ${ }^{7}$.

Evidence-based dentistry (EBD) is an approach to oral health care that requires the judicious integration of systematic assessments of clinically relevant scientific evidence relating to the patient's oral and medical condition and history, with the dentist's clinical expertise and the patient's treatment needs and preferences ${ }^{8-10}$.

Evidence-based clinical programs are systematically developed containing recommendations for the care of individuals by healthcare professionals that are based on the highest quality scientific evidence available. Guidelines are designed to help practitioners assimilate, evaluate and apply the ever-increasing amount of evidence and opinion on current best practice, and to assist them in making decisions of appropriate and effective care for their patients $^{11-13}$.

Hence there is sufficient strong evidence that pregnancy and childhood period are particularly important times to access oral health care, so it is recommended to apply appropriate oral health program for prevention of oral diseases and promote oral status of expectant mothers, her baby, preschool and school age children based on best evidence recommendations.

\section{MATERIAL}

Electronic search of English scientific papers from 2006 to 2016 was accomplished using the Cochrance library database, PubMed, the EviDents search engine, the EMBASE database, OVID, and the Science Citation Index database. The search terms used were expectant mother, pregnancy, pregnancy outcome, periodontal diseases, evidencebased dentistry, oral health care, oral health education, clinical recommendations.

\section{RESULTS}

Three hundred and eighty-two articles were reviewed as well as some references of selected articles. Seventy-four recent studies described the role of oral health in prevention of oral diseases and improvement of oral status of expectant mothers and their babies from birth throughout different school stages.

\section{DISCUSSION}

\section{Common oral problems of the expectant mother and her baby}

Lack of information or perceptions about the safety and importance of dental treatment during pregnancy lead to an ignorance of oral healthcare by dentists, physicians and pregnant women ${ }^{14}$. The two main common problems are periodontal diseases and dental caries.

\section{Effect of Pregnancy on Periodontal Condition}

Pregnancy has an impact factor on the periodontal health status. There is a relationship between periodontal diseases and increased risk of adverse pregnancy outcome. Destructive periodontal disease affects about $15 \%$ of women of childbearing age and up to $40 \%$ of pregnant women, with a disproportionate burden among low socio-economic status women ${ }^{15,16}$.

A reduction in blood immunoglobulins levels $(\mathrm{IgG})$ in the second trimester of pregnancy often leads to increased colonization by oral pathogens with increased potential for severe, sustained oral infections such as periodontal disease. Hormonal modifications (fluctuations in estrogen and progesterone levels) have been proposed to exacerbate gingival inflammation, to initiate changes in the composition of oral biofilm, and to induce a selective growth of periodontal pathogens such as gram-negative anaerobic bacteria as Porphyromonas gingivalis, Prevotella intermedia or Campylobacter rectus ${ }^{17}$. 
The most common periodontal conditions which may affect the pregnant woman include: Pregnancy gingivitis, Pregnancy tumor and Periodontitis ${ }^{18-25}$.

\section{Effect of Periodontal disease on Pregnancy}

A growing body of research has linked periodontal disease with preterm birth $(\mathrm{PB})$, low birth weight babies (LBW) or both and preeclampsia outcomes ${ }^{14,26,27}$.

\section{Evidence of periodontal disease and adverse preg- nancy outcome}

Bassani et $\mathrm{al}^{28}$ conducted a case control study on periodontal disease and perinatal outcomes. Their results do not support the hypothesis of association observed in previous studies after appropriate controlling for confounding variables. Agueda et $\mathrm{al}^{29}$ studied periodontal disease as a risk factor for adverse pregnancy outcomes. The factors involved in many cases of adverse pregnancy outcomes have still not being identified, although systemic infections may play a role. This study found a modest association between periodontitis and PB. In addition, Siqueira et $\mathrm{al}^{30}$ investigated maternal periodontitis as a potential risk variable for preeclampsia: a case and concluded that it is a risk factor associated with preeclampsia. Lin et $\mathrm{al}^{31}$ conducted a study on maternal periodontal disease of the relationships between porphyromonas gingivalis, serum, pro-inflammatory mediators and preterm low birth weight. There may be a possible link between periodontal diseases and PLBW. Also, Rakoto- Alson et $\mathrm{al}^{32}$ studied periodontal diseases, preterm births, and low birth weight and showed that there is a strong association among Periodontitis, PB, LBW. Vogt et $\mathrm{al}^{33}$ done a study on periodontal disease and some adverse perinatal outcomes in a cohort of low risk pregnant women. PD was a risk factor for PT, LBW among Brazilian low risk pregnant women. Based on the previous conducted studies, there is a positive relationship between periodontal disease and adverse pregnancy outcomes. The pathogenic bacteria responsible for periodontal disease induce secretion of a variety of chemical inflammatory mediators such as prostaglandins, interleukins, tumor necrosis factor- $\alpha$ and matrix metaloprotenase. Elevated levels of chemical mediators (PGE-2, ILs, TNF- $\alpha$, MMPs) can directly affect the pregnant woman. Furthermore, these chemical mediators have been found in the amniotic fluid of women with periodontitis and preterm birth compared with healthy control patients ${ }^{34-36}$.

The mechanism may be explained by the release of prostaglandins lead to restriction of placental blood flow and causes placental necrosis and resultant intrauterine growth restriction and high levels of prostaglandin in blood associated with uterine contractions leading to preterm deliveries ${ }^{19,37}$.

\section{Pregnancy and dental caries}

It has been hypothesized that pregnancy could increase the risk of caries initiation or progression, by changes in saliva composition ${ }^{38}$. Repeated nausea and vomiting (gastric reflux) as the oral cavity is exposed more often to gastric acid that can erode dental enamel and increase risk of dental caries, sugary dietary cravings, or less effective oral health care ${ }^{14,39}$.

However, given the relatively short time frame of pregnancy and the kinetics of dental caries progression, it is unlikely that tooth decay will develop from initial carious lesion to major tooth damage within this period ${ }^{40}$.

Indeed, pregnancy has never been clearly associated with an increased incidence of dental caries. Tooth decay often leads to painful and stressful situations, with negative effects on the quality of life of pregnant women. Better knowledge of tooth decay risk factors during pregnancy could help to develop follow-up protocols for women at risk, along with better prevention strategies.

Moreover, mothers with poor oral health and high levels of cariogenic oral bacteria are at greater risk for infecting their children with the bacteria and increasing their children's caries risk at an early age ${ }^{41}$. 


\section{Oral health problems of preschool-age children} and early childhood caries (ECC)

ECC is a public health problem that continuously affects infant and pre-school children worldwide. It is generally defined as a virulent form of dental caries in children younger than 6 years ${ }^{42,43}$. Dental caries in primary teeth is also predictive of future caries risk. The disease of ECC is the presence of one or more decayed (noncavitated or cavitated lesions), missing (due to caries), or filled tooth surfaces in any primary tooth in a child under the age of 6 years $^{43}$. In children, younger than 3 years of age, any sign of smooth-surface caries is indicative of severe early childhood caries (S-ECC). From ages 3 through 5 year, one or more cavitated, missing (due to caries), or filled smooth surfaces in primary maxillary anterior teeth or a decayed, missing, or filled score of $\geq 4$ (age 3 ), $\geq 5$ (age 4), or $\geq 6$ (age 5) surfaces constitutes $\mathrm{S}-\mathrm{ECC}^{44}$.

Usually, mothers are the main source of transmissible cariogenic bacteria. Mothers with poor oral health and high levels of cariogenic oral bacteria are at greater risk for infecting their children with the bacteria and increasing their children's caries risk at an early age. It has been shown that Streptococcus mutans (SM) of $70 \%$ mother and child are phenotypically and genotypically similar ${ }^{45}$.

It is well-established that mutans streptococci can be acquired and readily transferred through vertical transmission from mother to child or caregiver to child or through horizontal transmission from other members of a family or from child to child in daycare. Colonization can occur any time after the child is born, but the bacteria have the greatest potential for being retained in the mouth after a tooth eruption ${ }^{46}$.

Preschool children, have experienced a significant increase in caries prevalence in the primary dentition and once caries develops in young children, adverse outcomes such as dental pain, chewing difficulties, speech problems, general health disorders, psychological problems and new caries tend to occur. In addition, the treatment is expensive which may require general anesthesia for extraction $^{47}$.

Untreated dental caries can affect body weight, growth and quality of life in preschool children. Caries experience in early childhood has been linked to caries experience in the permanent dentition in several studies. The burden of dental caries lasts a lifetime because once the tooth structure is destroyed it will usually require restoration and ongoing maintenance throughout life ${ }^{42-48}$.

The characteristics of the family such as change in family status, education and national background, and parental lifestyle such as maternal weight and diet during pregnancy and early motherhood were consistently associated with caries development in preschool children. These caries risk indicators are known by health care personnel at the time when the mother has become pregnant, and may be used to identify risk children and target preventive care at children before dental caries has developed ${ }^{45}$.

\section{Common oral health problems of school-age children}

Among the most common oral health problems in school-age children are dental caries and periodontal diseases.

\section{Dental caries}

Current evidences show that dental caries is a multifactorial disease and complexly modulated by genetic, behavioral, social and environmental factors. Despite creditable scientific advances and the fact that caries is preventable, the disease continues to be a major public health problem predominantly affecting children. Dental caries is often responsible for the absenteeism from school and loss of working hours. The lack of availability of dental care, postponement of treatment due to cost considerations, and underutilization of available facilities not only results in aggravation of the disease but also enhances the cost of treatment and care $^{49}$. 
Worldwide schools offer an efficient and effective way to reach children and, through them, families and community members. School age is an influential stage in people's lives, a time when lifelong sustainable oral health-related behaviors, as well as beliefs and attitudes, are being developed. Children are particularly receptive to health messages during this period and the earlier the good habits are established, the longer lasting the impact. Moreover, the messages can be reinforced regularly throughout the school years ${ }^{50-53}$.

\section{Gingival and periodontal diseases}

One of the most common infectious diseases among children is gingival and periodontal diseases. Their clinical presentation may either be limited to the gingival component only or progress further to affect the entire periodontium. Epidemiological data suggest that the prevalence and severity of gingivitis in children increases with age and reaches peak by the time puberty sets in. The increase in severity is attributed to various factors, such as influence of hormones and various stages of eruption ${ }^{54}$.

Even though it is believed that periodontitis is age related, that is, more the age more severe the disease, it is not uncommon that more severe forms of periodontitis are seen in adolescents known aggressive periodontitis ${ }^{55}$.

Contrasting forms of periodontal disease can affect children and adolescents with varying prevalence, severity and extent, leading to a diverse prognosis in these age groups ${ }^{56}$.

\section{Evidence of oral health promotion interventions (Expectant mother)}

Michalowicz et $\mathrm{al}^{57}$ investigated the treatment of periodontal disease and the risk of preterm birth. The treatment of periodontitis in pregnant women was safe and effective in improving periodontal disease. However, it did not significantly alter the rates of preterm birth, low birth weight, fetal growth restriction, or preeclampsia. Also, Offenbacher et $\mathrm{al}^{58}$ conducted a pilot study on the effects of periodontal therapy during pregnancy on periodontal status (biologic parameters, and pregnancy outcomes). Treatment was safe, improved periodontal health and prevented periodontal disease progression. Reduction in the rate of preterm delivery. Sadatmansouri et $\mathrm{al}^{59}$ studied the effects of periodontal treatment phase I on birth term and birth weight. Periodontal therapy, phase I, results in a reduction in PLBW incidence rate. Therefore, the application of such a simple method among periodontally diseased pregnant women is recommended. In addition, Tarannum et $\mathrm{al}^{60}$ investigated the effect of periodontal therapy on pregnancy outcome in women affected by periodontitis. Periodontitis has an adverse pregnancy outcome. Study provides evidence that non-surgical periodontal therapy can reduce the risk for PLBW significantly. Newnham et $\mathrm{al}^{61}$ conducted a research on treatment of periodontal disease during pregnancy. The evidence provided by their study does not support the hypothesis that treatment of periodontal disease in mid-pregnancy prevents preterm birth, fetal growth restriction, or preeclampsia. Periodontal treatment during pregnancy is safe for the woman and her pregnancy, and that any beneficial effects for the child are either nonexistent or likely to be restricted to certain populations or subgroups that have yet to be defined with certainty.

From the previous RCTs, it was concluded that: Evidence suggest that non- surgical periodontal treatment including oral hygiene instructions with scaling and root planning is safe and effective in improvement of periodontal status during pregnancy. No conclusive evidence can be provided about the relation between treatment and the reduction of adverse pregnancy outcomes (PTB, LBW and preeclampsia). 


\section{Evidence of oral health promotion interventions} (Preschool-age children)

Weintraub et $\mathrm{al}^{62}$ examined fluoride varnish efficacies in preventing ECC. Fluoride varnish added to caregiver counseling is efficacious in reducing early childhood caries incidence. Feldens et $\mathrm{al}^{63}$ conducted a randomized trial of the effectiveness of home visits in preventing early childhood caries. Home visits for dietary advice appear to help reducing dental cries in infants. Also, they investigated the long-term effectiveness of a nutritional program in reducing ECC and found that home nutritional advice during the first year of life decreases caries incidence and severity at four years of age in a low-income community ${ }^{65}$. In addition, Slade et $\mathrm{l}^{66}$ examined the effect of health promotion and fluoride varnish on dental caries among Australian Aboriginal children and revealed that fluoride varnish was efficacious in preventing dental caries in young children. Pukallu et $\mathrm{al}^{67}$ conducted a randomized, controlled clinical trial comparing chlorhexidine gel and low-dose fluoride toothpaste to prevent early childhood caries. Tooth brushing using 3-4\% fluoride toothpaste with or without the application of chlorhexidine gel $(0.12 \%$ reduces ECC from $23 \%$ found in the general community to $5-7 \%$. The lack of effect with chlorhexidine is likely to be due to low compliance.

\section{Evidence of oral health promotion interventions (School-age children)}

Truin \& van'tHof ${ }^{68}$ tested the effect of fluoride gel on incipient carious lesions in a low- caries child population and found that there is no inhibiting effect on both enamel and dentine lesions in the permanent dentition of low-caries children. Also, Stecksén-Blicks et $\mathrm{al}^{69}$ investigated the effect of xylitol and xylitol-fluoride lozenges on approximal caries development in high-caries-risk children. Two years' trial did not support a self-administered regimen of xylitol or xylitol/fluoride-containing lozenges for the prevention of approximal caries in young adolescents with high caries risk. Moreover, Hausen et $\mathrm{al}^{70}$ investigated noninvasive control of dental caries in children with active initial lesions. The results show that by using a regimen that includes multiple measures for preventing dental decay, caries increment can be significantly reduced among caries-active children living in an area where the overall level of caries experiences low. In addition, Liu et $\mathrm{al}^{74}$ conducted a randomized trial on fluorides and sealants for fissure caries prevention and found that placement of resin sealant, semiannual application of $\mathrm{NaF}$ varnish, and annual application of SDF solution are all effective in preventing pit and fissure caries in permanent molars.

\section{CONCLUSIONS}

1- Evidence-based healthcare is the integration of clinical expertise, patient values and the reliable and precise use of current best evidence in making decision about the care of individual patients. This ultimately improves the quality of treatment the clinician can provide and the level of healthcare for the patient.

2- Maintaining good oral health improves the general health and well-being of women during pregnancy, may reduce adverse pregnancy outcomes and contributes to improving the oral health of their children.

3- Dental caries in infants is a disease that generally is preventable. Determining those mothers at highest risk for transferring cariogenic bacteria to their children improves opportunities for preventive intervention.

4- The importance of plaque control, both in gingivitis and periodontitis, remains the mainstay of prevention of periodontal disease in expectant mother, young children and adolescents.

5- The benefits of providing dental care during pregnancy far outweigh potential risks. 
Prevention, diagnosis and treatment of oral diseases, including needed dental radiographs and use of local anesthesia, are highly beneficial and can be undertaken during pregnancy with no additional fetal or maternal risk when compared to the risk of not providing care.

6- Evidence showed that improvement of oral health has a positive influence on quality of life of expected mother and her children (preschool and school age children).

\section{REFERENCES}

1. Wright JT, Crall JJ, Fontana M, Gillette EJ, Nový BB, Dhar $\mathrm{V}$ et al. Evidence-based clinical practice guideline for the use of pit-and-fissure sealants: A report of the American Dental Association and the American Academy of Pediatric Dentistry. J Am Dent Assoc. 2016; 147 (8): 672-682. e12. doi: 10.1016/j.adaj.2016.06.001.

2. Straus SE, Richardson WS, Glasziou P, Haynes RB. Evidence-based medicine: How to practice and tech EBM. $3^{\text {rd }}$ edn. Edinburgh: Churchill-Livingstone, 2005.

3. Padiyar N, Agrwal S, Tandon P. Evidence based dentistry: why and how? J Int Oral Health 2011; 3 (1): 1-6.

4. Sutherland SA and Matthews DC. Conducting systematic reviews and creating clinical practice guidelines in dentistry: lessons learned. J Am Dent Assoc 2004; 135 (6): 747-753.

5. Sathorn and Parashos P. Questions and answers in evidence-based patient care. British Dent J 2007; 203: 309-319.

6. Steves R and Hootman J. PMCID: PMC385266 EvidenceBased Medicine: What Is It and How Does It Apply to Athletic Training? J Athl Train 2004; 39 (1): 83-87.

7. Abhishek M, Gurkiran K, Gupta S. Evidence based dentistry - a new paradigm. Indian J D Sc 2011; 5 (3): 24-28.

8. Peto $R$ and Baigent $C$. Trials: the next 50 years. Large scale randomized evidence of moderate benefits. Br Med J 1998; 317: 1170-1171.

9. Bader J, Ismali A, Clarkson J (Editorial). Evidence-based dentistry and the dental research community. J Dent Res 1999; 78: 1480-1483.

10. Healey D and Lyons K. Evidence-based practice in dentistry. New Zealand Dent J 2002; 98: 32-35.
11. Shekelle PG, Woolf SH, Eccles M, Grimshaw J. Clinical guidelines: developing guidelines. Br Med J 1999; 318 (7183): 593-596.

12. Richards D, Clarkson J, Matthew D, Niederman R. Evidence-based dentistry: management information for better practice. $1^{\text {st }}$ ed. London; Quintessentials Publishing Co. Ltd; 2008.

13. Sackett D, Richardson WS, Glasziou P, Haynes R. Evidence-based medicine: How to practice and teach EBM. New York, Churchill-Livingstone, 1997.

14. Silk H, Douglass AB, Douglass JM, Silk L. Oral health during pregnancy. Amer Fam Physician 2008; 77:1139-1144.

15. Gürsoy M, Pajukanta R, Sorsa T, Könönen E. Clinical changes in periodontium during pregnancy and post-partum. J Clin Periodontol 2008; 35: 576-583.

16. Sarifakioglu E, Gunduz C, Gorpelioglu C. Oral mucosa manifestations in 100 pregnant versus non-pregnant patients: an epidemiological observational study. Eur J Dermatol. 2006; 16: 674-676.

17. Basha S, Shivalinga Swamy H, Noor Mohamed R. Maternal Periodontitis as a Possible Risk Factor for Preterm Birth and Low Birth Weight--A Prospective Study. Oral Health Prev Dent. 2015; 13 (6): 537-44.

18. Carrillo-de-Albornoz A, Figuero E, Herrera D, and Bascones-Martinez A. Gingival changes during pregnancy: II. Influence of hormonal variations on the subgingival biofilm. J Clin Periodontol 2010; 37 (3): 230-240.

19. Yokoyama M, Hinode D, Yoshioka M, Fukui M, Tanabe S, Grenier D, et al. Relationship between Campylobacter rectus and periodontal status during pregnancy. Oral Microbiol and Immunolog 2008; 23 (1): 55-59.

20. Clothier B, Stringer M, Jeffcoat MK. Periodontal disease and pregnancy outcomes: Exposure, risk and intervention. Best Pract Res Clin Obstet Gynaecol 2007; 21 (3): 451-466.

21. Gừrsoy M, Pajukanta R, Sorsa T, Könönen E. Clinical changes in periodontium during pregnancy and postpartum. J Clin Periodontol 2008; 35 (7): 576-583.

22. Khanna S and Shalini M. Pregnancy and oral health: Forgotten Territort Revisited. J Obstet Gynecol India 2010;60 (2): 123-127.

23. Markou E, Eleana B, Lazaros T, Antonios, K. The influence of sex steroid hormones on gingiva of women. Open Dent J. 2009; 3: 114-119. 
24. Xiong X, Buekens P, Fraser WD, Beck J, Offenbacher S. Periodontal disease and adverse outcomes: A systematic review. Int J Obstet Gynecol 2006; 113 (2): 135-143.

25. Jiang $\mathrm{H}$, Xiong X, Buekens $\mathrm{P}, \mathrm{Su} \mathrm{Y}$, Qian X. Use of mouth rinse during pregnancy to improve birth and neonatal outcomes: a randomized controlled trial. BMC Pregnancy Childbirth. 2015; 15:311. doi: 10.1186/s 12884-015-0761-3.

26. Walia M, Saini N. Relationship between periodontal diseases and preterm birth: Recent epidemiological and biological data. Int J Appl Basic Med Res. 2015; 5 (1): 2-6. doi: 10.4103/2229-516X.149217.

27. Dashash M, Nugent J, Baker P, Tansinda, D, Blinkhorn F. Interleukin-6-174 genotype, periodontal disease and adverse pregnancy outcomes: a pilot study. J Clin Immunol 2008; 28 (3): 237-243.

28. Bassani DG, Olinto MTA, Kreiger N. Periodontal disease and perinatal outcomes: a case control study. J Clin Periodontol 2007; 34: 31-39.

29. Agueda A, Ramon JM, Manau C, Guerrero A, Echeverria JJ. Periodontal disease as a risk factor for adverse pregnancy outcomes: a prospective cohort study. J Clin Periodontol 2008; 35: 16-22.

30. Siqueira FM, Cota LO, Costa JE, Haddad JP, Lana AM, Costa FO. Maternal periodontitis as a potential risk variable for preeclampsia: a case-control study. J Periodontol. 2008; 79 (2): 207-215.

31. Lin Y, Tan ZR, Chen HB, Tai BJ, Jiang H, Du MQ. Study on maternal periodontal disease of the relationships between porphyromonas gingivalis, serum, pro-inflammatory mediators and preterm low birth weight. West China J Stomatol 2009; 27 (6): 595-598.

32. Rakoto-Alson S, Tenenbaum H, Davideau JL. Periodontal diseases, preterm births, and low birth weight: findings from a homogeneous cohort of women in Madagascar. $\mathrm{J}$ Periodontol 2010; 81(2): 205-213.

33. Vogt M, Sallum A, Cecatti J and Morais S. Periodontal disease and some adverse perinatal outcomes in a cohort of low risk pregnant women. Reproductive Health 2010; $7: 29$.

34. Andrukhov O, Ulm C, Reischl H, Nguyen PQ, Matejka M, Rausch-Fan X. Serum cytokine levels in periodontitis patients in relation to the bacterial load. J Periodontol 2011; 82 (6): 885-892.
35. Casarin RCV, Del Peloso, Ribeiro E, Mariano FS, Nociti FH, Casati MZ, et al. Levels of Aggregatibacter actinomycetemcomitans, Porphyromonas gingivalis, inflammatory cytokines and species-specific immunoglobulin $\mathrm{G}$ in generalized aggressive and chronic periodontitis. J Periodontol Res 2010; 45 (5): 635-642.

36. Pressman EK, Thornburg LL, Glantz JC, Earhart A, Wall $\mathrm{PD}$, Ashraf M, et al. Inflammatory cytokines and antioxidants in midtrimester amniotic 8 Journal of Pregnancy fluid: correlation with pregnancy outcome. Am J Obstet Gynecol 2011; 204 (2): 155e1-155e7.

37. Shanthi V, Vanka A, Bhamba A, Saxena V, Saxena S, Kumar S. Association of pregnant women periodontal status to preterm and low-birth weight babies: A systematic and evidence-based review. Dent Res J (Isfahan) 2012; 9(4): 368-380.

38. Dellinger TM and Livingston HM. Pregnancy: physiologic changes and considerations for dental patients. Dent Clin North Am 2006; 50 (4): 677-697.

39. Kuramitsu HK. Molecular genetic analysis of the virulence of oral bacterial pathogens: an historical perspective. Crit Rev Oral Biol Med.2003; 14 (5): 331-344.

40. Vergnes JN, Kaminski M, Lelong N, Musset AM, Sixou $M$, Nabet C. Frequency and risk indicators of tooth decay among pregnant women in France: a cross-sectional analysis. PLoS One. 2012; 7 (5): e33296. doi: 10.1371/ journal.pone.0033296. Epub 2012 May 7.

41. Drury TF, Horowitz AM, Ismail AI, Maertens MP, Rozier RG, Selwitz RH. Diagnosing and reporting early childhood caries for research purposes. A report of a workshop sponsored by the National Institute of Dental and Craniofacial Research, the Health Resources and Services Administration, and the Health Care Financing Administration. J Public Health Dent 1999; 59 (3): 192-197.

42. Allareddy V, Nalliah RP, Haque M, Johnson H, Rampa SB, Lee MK. Hospital-based emergency department visits with dental conditions among children in the United States: nationwide epidemiological data. Pediatr Dent. 2014; 36 (5): 393-9.

43. Zafar S, Harnekar S, Siddiqi A. Early childhood caries: etiology, clinical considerations, consequences and management. Int Dent Sa 2009; 11; (4): 24-36.

44. Lucey SM. Oral health promotion initiated during pregnancy successful in reducing early childhood caries. Evid Based Dent 2009;10 (4): 100-101. 
45. Wigen TI and Wang NJ. Parental influences on dental caries development in preschool children. An overview with emphasis on recent Norwegian research. Norsk Epidemiologi 2012; 22 (1): 13-19.

46. Tickle M, Blinkhorn AS, Milsom KM. The occurrence of dental pain and extractions over a 3-year period in a cohort of children aged 3-6 years. J Public Health Dent 2008; 68:63-69.

47. Milsom KM, Blinkhorn AS, Tickle M. The incidence of dental caries in the primary molar of young children receiving National Health Service funded dental care in practices in the north west of England. Br Dent J 2008; 205:384-385.

48. Sheiham A. Dental caries affects body weight, growth and quality of life in pre-school children. Br Dent J 2006; 201: 625-626.

49. Christensen LB, Twetman S, Sundby A. Oral health in children and adolescents with different socio-cultural and socioeconomic backgrounds. Acta Odontol Scand 2010; 68: $34-42$.

50. Ditmyer M, Dounis G, Mobley C, Schwarz E. A casecontrol study of determinants for high and low dental caries prevalence in Nevada youth. BMC Oral Health 2010; 10: 24 .

51. Warren JJ, Weber-Gasparoni K, Marshall TA, Drake DR, Dehkordi-Vakil F, Dawson DV, et al. A longitudinal study of dental caries risk among very young low SES children. Community Dent Oral Epidemiol 2009; 37:116-122.

52. Fejerskov O, Kidd E, Edwina AM. Dental caries: The disease and its clinical management. 2nd ed. Wiley-Blackwell; 2008.

53. Shailee F, Sogi GM, Sharma KR, Nidhi P. Dental caries prevalence and treatment needs among 12-and 15-year old schoolchildren in Shimla city, Himachal Pradesh, India Indian. J Dent Res 2012; 23 (5): 579-584.

54. Masamatti SS, Kumar A, Virdi MS. Periodontal diseases in children and adolescents: a clinician's perspective part. Dent Update.2012; 39 (8):541-544.

55. Gupta S. Prevention of periodontal diseases in children and adolescents - health promotion and behavioral approaches. JIDA 2011; 5(6): 762-766.

56. Albandar JM, Muranga MB, Rams TE. Prevalence of aggressive periodontitis in school attendances in Uganda. $\mathrm{J}$ Clin Periodontol 2002; 29: 823-831.
57. Michalowicz BS, Hodges JS, DiAngelis AJ, Lupo VR, Novak MJ, Ferguson JE et al. Treatment of periodontal disease and the risk of preterm birth. N Engl J Med 2006; 355 (18):1885-1894.

58. Offenbacher S, Lin D, Strauss R, McKaig R, Irving J, Barros SP. Effects of periodontal therapy during pregnancy on periodontal statusbiologic parameters, and pregnancy outcomes: a pilot study. J Periodontol 2006; 77 (12): 2011-2024.

59. Sadatmansouri S, Sedighpoor N, Aghaloo M. Effects of periodontal treatment phase I on birth term and birth weight. J Indian Soc Pedod Prev Dent 2006; 24 (1): 23-26.

60. Tarannum F and Faizuddin M. Effect of periodontal therapy on pregnancy outcome in women affected by periodontitis. J Periodontol 2007; 78 (11): 2095-2103.

61. Newnham JP, Newnham IA, Ball CM, Wright M, Pennell $\mathrm{CE}$, Swain J et al. Treatment of periodontal disease during pregnancy: a randomized controlled trial. Obstet Gynecol 2009; 114 (6): 1239-1248.

62. Weintraub JA, Ramos-Gomez F, Jue B, Shain S, Hoover CI, Featherstone JD, et al. Fluoride varnish efficacy in preventing early childhood caries. J Dent Res 2006; 85 (2): 172-176.

63. Feldens CA, Vítolo MR, Drachler Mde L. A randomized trial of the effectiveness of home visits in preventing early childhood caries. Community Dent Oral Epidemiol 2007; 35 (3):215-223.

64. Whittle JG, Whitehead HF, Bishop CM.A randomized control trial of oral health education provided by a health visitor to parents of pre-school children. Community Dent Health 2008; 25 (1): 28-32.

65. Feldens CA, Giugliani ER, Duncan BB, Drachler Mde L, Vítolo MR. Long-term effectiveness of a nutritional program in reducing early childhood caries: a randomized trial. Community Dent Oral Epidemiol 2010; 38 (4): 324-332.

66. Slade GD, Bailie RS, Roberts-Thomson K, Leach AJ, Raye I, Endean C, et al. Effect of health promotion and fluoride varnish on dental cries among Australian aboriginal children: results from a community-randomized controlled trial. Community Dent Oral Epidemiol 2011, 39: 29-43.

67. Pukallus ML, Plonka KA, Barnett AG, Walsh LJ, Holcombe TF, Seow WK. A randomized, controlled clinical trial comparing chlorhexidine gel and low-dose fluoride toothpaste to prevent early childhood caries. Int J Paediatr Dent 2013; 23 (3): 216-224. 
68. Truin GJ and van'tHof M. The effect of fluoride gel on incipient carious lesions in a low-caries child population. Community Dent Oral Epidemiol 2007; 35 (4): 250-254.

69. Stecksén-Blicks C, Holgerson PL, Twetman S. Effect of xylitol and xylitolfluoride lozenges on approximal caries development in high-caries-risk children. Int J Paediatr Dent 2008; 18 (3):170-177.

70. Hausen H, Seppa L, Poutanen R, Niinimaa A, Lahti S, Kärkkäinen S, et al. Noninvasive control of dental caries in children with active initial lesions. A randomized clinical trial. Caries Res 2007; 41(5): 384-391.

71. Kervanto-Seppälä S, Lavonius E, Pietilä I, Pitkäniemi J, Meurman JH, Kerosuo E. Comparing the caries-preventive effect of two fissure sealing modalities in public health care: a single application of glass ionomer and a routine resin-based sealant programme. A randomized split-mouth clinical trial. Int J Paediatr Dent 2008; 18 (1): 56-61 .

72. Baseggio W, Naufel FS, Davidoff DC, Nahsan FP, Flury S, Rodrigues JA. Caries-preventive efficacy and retention of a resin-modified glass ionomer cement and a resin-based fissure sealant: a 3-year split-mouth randomized clinical trial. Oral Health Prev Dent 2010; 8 (3): 261-268.

73. Stokes E, Ashcroft A, Burnside G, Mohindra T, Pine CM. Randomised controlled trial ofthe efficacy ofa highfluoride gel selfapplied by toothbrushing inchildren at high caries risk. Caries Res 2011; 45 (5): 475-485.

74. Liu BY, Lo EC, Chu CH, Lin HC. Randomized trial on fluorides and sealants for fissure caries prevention. J Dent Res 2012; 91 (8): 753-758. 